\title{
Revista Aisthesis: tres tiempos para un itinerario filosófico informal
}

\author{
Gabriel Castillo Fadic \\ Instituto de Estética, Facultad de Filosofía, Pontificia Universidad Católica de Chile. \\ gcastilf@uc.cl \\ Román Domínguez Jiménez \\ Instituto de Estética, Facultad de Filosofía, Pontificia Universidad Católica de Chile. \\ rdoinguezj@uc.cl
}

La historia de la filosofía en Chile, y probablemente también en gran parte de Iberoamérica, oscila, grosso modo, entre una vertiente formal y explícitamente tributaria del canon occidental de la disciplina, y otra vertiente informal que ha sido relegada a distintas nomenclaturas, planos y circuitos teóricos no reconocidos como auténticamente filosóficos. Aunque podría simplemente pensarse que la primera variante corresponde al modo en que Occidente ha asimilado la escritura y el estudio de la filosofía, mientras que la segunda da cuenta de un modo inespecífico de hacer teoría al margen del orden occidental; en realidad, ambas, y por sobre todo la separación insalvable que se ha establecido entre ellas, constituyen las dos caras de una misma moneda que ilustra la excentricidad, los descalces, los anacronismos, el autismo y la dependencia de la práctica filosófica regional. El rasgo que la homogeneiza es su adhesión acrítica a la imagen pretendida de una filosofía occidental, que se asume como el horizonte insuperable de su posibilidad de enunciación. Erigida en su límite y en su mito epistemológico, la filosofía regional ha amparado una extraordinaria capacidad para eludir todo vínculo directo con un objeto inmediato que le permita establecer conscientemente una escritura territorial ${ }^{1}$.

1 En una de las tantas imágenes posibles, el chileno Patricio Marchant afirmaba en 1970 que "trabajamos sobre filosofías que recibimos con bastantes años de retardo, sin un conocimiento adecuado de sus raíces, productos extraños que los libreros se dignan dejarnos caer: hemos sido y somos la conciencia teórica de libreros e importadores de libros. Concretamente, hemos sufrido la extensa y nefasta influencia de la obra de José Ortega y Gasset, y más de una generación fue (des)formada bajo su alero. Tal (des)formación, entre otras cosas, antropologizó el pensamiento de Heidegger (que así interpretado tuvo y tiene una gran influencia especialmente entre espíritus distinguidos), rebajó la filosofía de Nietzsche a una superficial 'filosofía de la vida', nos mantuvo en una ignorancia total de Freud y la semiología. Posteriormente llegaron a nuestras manos algunas obras de Marx; no cualquiera sino los manuscritos de 1844 [...] preferimos leer las paráfrasis marxistas e ignoramos los textos de Feuerbach en los cuales Marx en esa época se apoyaba [...]. Los humanistas marxistas celebraron regocijada alianza con Hegel, 
Aun la pretensión de la filosofía continental de volverse geopolíticamente sobre sí misma para incorporar el problema de la "identidad cultural" ha implicado, en la medida en que supone una deriva perversa hacia la adhesión a un sujeto colectivo, muchas veces incluso nacional, una reafirmación negativa o indirecta, y muchas veces exotista, del paradigma occidentalista. Aquí residen finalmente las poderosas y limitantes fuerzas reactivas de la filosofía, que nos parecen dominantes en la cultura intelectual americana ${ }^{2}$.

La preeminencia de las fuerzas reactivas apenas designa como potencia y como posibilidad el deseable surgimiento de fuerzas activas. Pero los intentos más profundos por establecer una autonomía de método sobre la base de un objeto problemático específico raramente provienen de la tradición académica. Lo hacen, más bien, de lo que podríamos llamar una tradición filosófica informal: la del ensayo, la del manifiesto o el aforismo programático, la del diario íntimo. No parece exagerado pensar que, si existe una inteligencia filosófica en América, en acto o en potencia, no es en la filosofía donde hay que buscarla sino, precisamente, en este descalce informal de la escritura ${ }^{3}$. Descalce no obstante insuficiente, errático, incompleto. Aun en su informalidad, tal escritura privilegia el monólogo sin respuesta con su referente occidental (nunca es su interlocutor, ni mucho menos su colega, sino su compilador acrítico) y desestima su participación en una comunidad interconectada.

Con sus sorpresivos aciertos y su cuantiosa precariedad, revista Aisthesis ofrece, desde la perspectiva de una eventual contribución disciplinaria, un itinerario tan disperso como ejemplar de los elementos que han tensionado en Chile un discurso filosófico. Desde su fundación, en 1966, tal itinerario se articula a nuestro juicio sobre tres grandes ciclos que no implican cesuras categóricas y abruptas entre ellos, sino transiciones lentas y encabalgadas.

cuyo estudio comenzó en forma vacilante, desde una perspectiva no crítica, idealista y alienante. La traducción de Sartre -con su doble ignorancia de Freud y Marx- contribuyó decisivamente a que la pequeña burguesía se extasiara con su libertad, destruyendo el supuesto mecanismo y materialismo freudiano-marxista...Y todo esto pensado al modo de la Historia de las Ideas, del Reino de la Razón, del Reino del Espíritu (reinos en los cuales se encuentran once mil vírgenes): no teníamos remedio. [...] Aquí y allá algunos profesores se dieron cuenta de que lo que enseñaban no tenía nada que ver con la realidad, o más exactamente, estaba destinado a ocultarla". Véase Patricio Marchant, La situación de la filosofía en Chile, 1970.

2 Cf. Gabriel Castillo Fadic, "Gestos reactivos y potencias activas en las filosofías informales de Hispanoamérica”, en Trayectorias hispanoamericanas. Santiago: Publicaciones Aisthesis, 2012.

3 Respecto a la noción de una inteligencia propiamente americana, puede consultarse el texto de Alfonso Reyes, "Notas para una inteligencia americana", publicado originalmente en el No. 24 de la mítica revista Sur (Año VI, septiembre 1936): "Hablar de civilización americana sería, en el caso, inoportuno; ello nos conduciría hacia las regiones arqueológicas que caen fuera de nuestro asunto. Hablar de cultura americana sería algo equívoco; ello nos haría pensar solamente en una rama del árbol de Europa trasplantada al suelo americano. En cambio, podemos hablar de la inteligencia americana, su visión de la vida y su acción en la vida. Esto nos permitiría definir, aunque sea provisionalmente, el matiz de América". Si ya la eventualidad de una inteligencia americana o panamericana tal y como la vislumbra Reyes parece hoy día difícil de aprehender o caracterizar, parece todavía más arduo conjeturar el eventual tono filosófico de dicha inteligencia, pues Reyes invoca una inteligencia común a las Américas y no a la sola América Ibérica. ¿Habría algo así como un substrato filosófico común al continente, una especie de matriz que, aunque occidental, sería distinta de la europea? En todo caso no se trataría de constatar que sí habría filosofías americanas (el pragmatismo estadounidense, la filosofía de la liberación de Dussel), sino de pensar que sí habría un modo de accionar, una configuración, un modo de relación y apropiación de la filosofía territorialemente americano, con matiz americano, o mejor dicho, como una ruptura filosófica americana. 
El primero de ellos va desde 1966 hasta 1981, o incluso 1983, y está determinado primero por la presencia y luego por la proyección del sacerdote croata Raimundo Kupareo, fundador del Instituto de Estética y formador de la primera generación de docentes e investigadores de la unidad. A pesar de que Kupareo regresa a Croacia en 1971 después de permanecer veintiún años en Chile, mantiene su presencia sistemática como autor hasta el número 15; y si bien casi todas sus contribuciones involucran una bajada a alguna forma expresiva de las artes, todas ellas dan cuenta también de un propósito filosófico autónomo e informado, que, incluso recurriendo a autores contemporáneos como Sartre o Foucault, aspira en última instancia a una proyección de la tradición escolástica.

Destacamos, por ejemplo, los artículos "Dramatología" (no 1), "El tiempo y el espacio novelescos" ( $n^{\circ} 3$ ), "Filosofía de la arquitectura" ( $\left.{ }^{\circ} 4\right)$, "La muerte del arte" (no 10), "La belleza natural" ( $\left.n^{\circ} 12\right)$ y "El imaginismo" ( $\left.{ }^{\circ} 13\right)$. Este primer ciclo está igualmente marcado por la recurrencia tanto de artículos confesionales como de tradición tomista. Mencionamos, por ejemplo, "Dios en el teatro actual", de Nicolás Dobrée ( $\left.{ }^{\circ} 1\right)$, además de las numerosas contribuciones del sacerdote conservador Osvaldo Lira, como "Splendor Formae" (no 2), "El arte y la moral" (n 7 ) y "Belleza y experiencia” ( $\left.n^{\circ} 10\right)$. Por último, cabe también resaltar las colaboraciones del fraile mercedario vinculado a los Legionarios de Cristo, Alfonso López Quintás, como por ejemplo "El objetivismo artístico y su trasfondo filosófico" ( $\left.\mathrm{n}^{\circ} 12\right)$.

No se trata, no obstante, de un ciclo privativamente conservador y de tanto en tanto podemos observar colaboraciones de teóricos de mediano prestigio internacional, como Herbert Read, quien escribe "El pensamiento crítico" en Aisthesis 2; Maurice Nedoncelle, uno de los principales exponentes del "personalismo" en Francia, quien publicó "De la inspiración como iniciación a la trascendencia" ( $\left.n^{\circ} 7\right)$; y Etienne Souriau, cuyo artículo "Educación por el arte y amplitud psíquica" apareció también en el número 7 de la revista.

El segundo ciclo está marcado por la influencia de Fidel Sepúlveda Llanos y su enorme trabajo de recuperación teórica de la producción simbólica vernacular, que podríamos situar entre comienzos de los años ochenta y el 2006, año de su muerte. Pensamos que un hito de transición es la aparición del número 14 de Aisthesis, en 1982, con el rótulo de "Estética y vida", el cual consolida la personalidad de Sepúlveda como un intelectual emergente y como un creativo renovador de un pensamiento estético que se pretenderá territorial y autónomo. Sin mencionar sus muy numerosas publicaciones, podríamos sostener que este ciclo está caracterizado por una antropologización del discurso filosófico. Los números 15, 16, 20 y 22 de Aisthesis están íntegramente consagrados a las relaciones entre "Estética y folklore”; y el número 17, a "Estética y mito".

Vemos también, en este segundo ciclo, un repliegue y un comentario sobre el aporte de autores de generaciones anteriores en la comprensión de la cultura local, propósito que posee siempre, a pesar de su deriva a las ciencias sociales, una marca 
filosófica. Radoslav Ivelic, por ejemplo, publica en Aisthesis 18, "Cuatro filósofos chilenos frente al misterio del arte" (consagrado a Osvaldo Lira, Luis Oyarzún, Félix Schwartzman y Raimundo Kupareo). La fuerza del motivo antropológico e identitario se hace manifiesto en Aisthesis 27 (1994), consagrada a "Estética e identidad cultural". Creemos que este ciclo experimenta desde entonces una cierta desorientación, un desperfilamiento de su línea, que durará hasta el año 1998, cuando comienza un tercer ciclo, quizás más riguroso y también más sintético, en donde la escritura filosófica regresa no solo revelando una mayor actualización ante los grandes debates contemporáneos de la estética, sino que también utilizando estos materiales en una reterritorialización menos dependiente de la exigencia folclorizante o identitaria.

Aisthesis 31, de 1998, incluye un largo texto sobre la situación de la estética filosófica en América en el siglo xx, pero también un artículo de Renate Reschke sobre la representación de lo postmoderno en Europa. Se hacen desde entonces cada vez más frecuentes las colaboraciones externas, lo que se acrecentará luego en los años 2000, ante las nuevas exigencias de indización. Carla Cordua publica "Sentido y sin sentido" en Aisthesis 33. En el número 34, Katya Mandoki publica "Análisis paralelo en la poética y la prosaica: un modelo de estética aplicada", y Gabriel Castillo, que se incorpora a la planta académica en 1998, presenta el primero de una serie de artículos que buscan establecer los principios de una fenomenología del espacio de Santiago ("Santiago, lugar y trayecto: la dialéctica del centro").

En los años 2000, podemos ver un esfuerzo sostenido por acrecentar el rigor y la presencia de contribuciones filosóficas originales, incluyendo números monográficos sobre cine y filosofía o fotografía y filosofía. Destacamos "La disolución del futuro", de José Jiménez, y "El gusto estético en la sociedad posindustrial”, de Carlos Fajardo, junto a un extenso texto de Gabriel Castillo, que busca situar a la llamada "Teoría Crítica" en el contexto de las sociedades preindustriales ("Negatividad, esperanza y margen en la estética de Theodor W. Adorno").

Mencionemos también en un registro clásico, "Sin lugar a una tesis. El fin del discurso a través de Martín Heidegger" (no 41), y las aplicaciones de la filosofía de Deleuze a la comprensión de algunos ritos vernaculares en el artículo escrito en conjunto por Gabriel Castillo Fadic, Patricio de la Cuadra, Benoît Fabre y François Blanc, "Sonido Ritual, Campo de Fuerza y Espacialidad Existencial: Una Estética no Musicológica de los Bailes Chinos" (n 48).

Desde el número 49, del 2012, hay una franca reorientación a la estética filosófica. Así lo prueba el dossier editado por José Pablo Concha en el número 52 sobre técnica y estética, cuyo texto introductorio se titula "Hacia una Estética Técnico Política”. Sebastián Gómez, destacado ex-alumno y filósofo radicado en Alemania, publica "Tecno-bíos: una aproximación biopolítica a la relación cuerpo-máquina en el contexto cibercultural contemporáneo". Aisthesis 53, del 2013, ofrece contribuciones a la estética en Lévinas, mientras que en el número siguiente, se publican textos sobre el problema de la inmanencia (Juan Pablo Esperón); sobre "La escritura 
del cogito: una hipótesis de Samuel Beckett” (Sergio Rojas); sobre la metafísica del espacio; sobre lo ominoso freudiano en Conrad; sobre Nietzsche en sus citas literarias modernas; y sobre Cyborg art y bioética. Destacamos también, en el número 56, algunos textos sobre filosofía de las imágenes, sobre "Sublimidad e imaginación en el combate tierra-mundo: una lectura existencialista de la desgarradura del arte en Heidegger" y sobre las implicaciones de lo sublime en la contemporaneidad. Por último, resaltamos que los números 57 y 58, del 2005, comportan textos originales sobre Lúkacs, Derrida y Heidegger.

\section{Corolario}

En un texto anterior, hemos sostenido que en las sociedades americanas, y particularmente en Chile, la filosofía, como actividad profesional, comienza precisamente allí donde la amistad termina, generando una disociación insuperable entre la amistad, en cuanto grupo jubilatorio e incluso creativo, y la composición filosófica, como si la filosofía solo pudiera erigirse en la supresión misma de los objetos inmediatos que surgirían de la intuición de la cercanía, de la frecuentación, de la tertulia, del viaje exploratorio, del periplo culinario, etílico. Allí donde escriben los poetas, los filósofos abandonan la filosofía. Punto de renuncia donde la escritura se asume como pura ficción, o como pura metáfora. Manuel Lacunza sueña con sus comidas y sus amigos que visita uno a uno, antes de volverse por otros veinte años, y hasta la muerte, a su exilio en Imola ${ }^{4}$. Molina y Garmendia se entera de la actividad ensayística de Alejandro Venegas, su compañero de curso, y lee sus obras, sus imágenes de la enfermedad de Chile en Sinceridad y en Por propias y extrañas tierras, o las de un Cristo mendigo que se avergüenza de los procesionantes que proclaman santo a un Dios de los ejércitos en La procesión del corpus, pero esas imágenes no son operativas en su historia de la filosofía ${ }^{5}$. Luis Oyarzún constituye su comunidad de amigos y discípulos con Jorge Millas, con Nicanor Parra, con Enrique Lihn, con Roberto Humeres, con Lafourcade, pero ¿cómo se incorpora la experiencia, el viaje a Tiltil

4 "En cinco meses de un viaje felicísimo llego a Valparaíso y habiéndome hartado de pejerreyes, y jaivas, de erizos y de locos, doy un galope a Santiago; hallo viva a mi venerable abuela; le beso la mano; la abrazo; lloro con ella [...] busco entre tanta muchedumbre a mi madre y no la hallo, busco a Madalena y no la hallo, busco a Domingo, a Solascasas, a Varela, a mi compadre don Nicolás, a Azúa, a Pedrito y a mi ahijada la Pilar., y no los hallo [...]. No obstante, por no perderlo todo, me vuelvo a la cuadra que hallo llena de gente, procuro divertirme y alegrarme con todos; les cuento mil cosas de por acá, téngolos embobados con mis cuentos; cuando no hallo más que contar miento a mi gusto; entre tanto les como sus pollos, su charquicán y sus cajitas de dulce y también los bizcochuelos y ollitas de Clara y de Rosita. Y habiendo llenado mi barriga para otros veinte años, me devuelvo a mi destierro por el mismo camino y con la misma facilidad. Mas antes de embarcarme en Valparaíso despierto y me hallo en cama". Fragmento de carta fechada en Imola, 9 de octubre de 1788. Revista de Historia y Geografía, Santiago, tomo IX, y reproducida en Antonio Rocco del Campo, Tradición y leyenda de Santiago. Santiago: Ercilla, 1941.

5 Una tónica que podría seguirse tanto en sus propósitos enciclopédicos, como en los ensayos de Filosofía Americana (Paris: Garnier, 1912), y también en aquellos directamente testimoniales, como en Estudios y recuerdos (Concepción: Atenea-Nascimento, 1939). 
y de Tiltil a Caleu, el viaje por los cerros de la costa?, ¿cómo ingresa en la escritura filosófica? Simplemente no ingresa, permanece sistemáticamente afuera y cuando ingresa, la autoconsciencia se niega ya a considerar la escritura como propiamente filosófica y la relega al epistolario, al diario íntimo.

La omisión de la amistad, como comunidad productora de objeto, como comunidad generadora y como comunidad crítica, suprime de entrada el nexo posible con la filosofía, la separa de su trama orgánica, de su narración de sí. En otras palabras, la aísla de su función mítica, entendiendo por mito, literalmente, como prescribe su etimología, la trama, el argumento, el sustrato narrativo ${ }^{6}$.

La filosofía profesional empieza a escribirse en América solo cuando ha olvidado su trama, cuando ignora dónde hallarla y menos sabe cómo recomponerla. Mario Góngora, así como antes Lastarria y Jorge Millas, vieron en su ausencia de sustrato mítico una marca de imposibilidad filosófica. Pero es en el predominio del gesto reactivo que se considera al mito como una trama prefabricada, a lo sumo interpretable por la filosofía, cuando en realidad la identidad móvil de dicha trama no la preexiste, sino que aparece, se revela, naturalmente, en la filosofía que asume desde el comienzo la exigencia de su propia trama. Una primera trama, ya no de reacción, sino de acción, de composición. El primer mito instalado es el mito mismo de su epistemología como administración acrítica del método.

¿Es posible aspirar al menos a una potencia filosófica?

En el mejor de los casos, nuestra tradición es prefilosófica. No ha encontrado aún su objeto propio, ni mucho menos ha podido establecer el lenguaje que haga a su objeto mostrarse a sí mismo y a partir de sí mismo. No ha encontrado un mundo, ni una trama, no ha inventado conceptos, no ha creado ni ha sido capaz, en un último recurso, de hacer de su falla, de su imitación, de su recepción pasiva, una falla lúcida, como indicaría la relectura de Zea del tópico de Calibán (Discurso desde la marginación y la barbarie). ¿Es posible superar el límite actual de la representación como administración de una imagen de Occidente?

La filosofía hispanoamericana surge de la puesta en obra de sus fuerzas de reacción. Reacción resentida a las imágenes de la filosofía Occidental, reacción al lugar mismo de Occidente, que vive como un inalcanzable más allá fenomenal. Reacción que compone y alimenta el sustrato mismo de buena parte de teorías con pretensión iberoamericana que gozan de cierto prestigio hoy día, como la Filosofía de la liberación de Dussel y el grupo Modernidad / Colonialidad del mismo Dussel, Mignolo y Quijano. En ese gesto se disocia de su nervadura interna que debería comenzar naturalmente por la aceptación de su desfase, de su refracción, de su falla lúcida, antes de encontrar, como hasta ahora se ha pretendido, el camino de su autonomía,

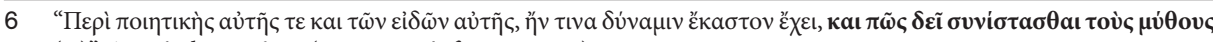
(...)". Aristóteles, Poética (1447a-10, énfasis nuestro). 
e incluso, el de su otredad. Su carácter reactivo la disocia, por una parte, aun a pesar de aportes importantes como el ethos barroco del esteta marxista Bolívar Echeverría, de la recomposición del mito, vale decir, de la recuperación de la trama de sí misma y, por otra parte, de los círculos de lectura y escritura en la amistad, que la orientarían a la comprensión misma de su etimología. Solo el restablecimiento de esta triple alianza -autorreflexión sobre su representación de Occidente, recuperación de la trama y saber en la amistad-podrían despertarla a sus potencias activas, desde las cuales, en un lugar que aún no existe, ella pudiera revertir la dicotomía histórica de América como relación excéntrica para un centro sin relato. 